\title{
Alcohol dependence and mood state in a population receiving methadone maintenance treatment
}

\author{
Edward MacManus, Clare Fitzpatrick
}

Ir J Psych Med 2007; 24(1): 19-22

\begin{abstract}
Objectives: The aim of this study was to assess the prevalence of alcohol dependence and anxiety and depressive disorder symptomatology among heroin users in drug treatment.

Method: Fifty-five clients on methadone maintenance treatment programmes in Dublin were interviewed.

Results: Prevalence rates were found to be $56 \%[n=31]$ for alcohol dependence, $56 \%[n=31]$ for anxiety disorder symptomatology, and $42 \%$ [ $n=23]$ for depressive disorder symptomatology. This finding of comorbid alcohol dependence and psychopathology among methadone maintenance treatment clients suggests that both clients' health and methadone maintenance treatment participation and completion rates may be compromised.

Conclusions: Alcohol dependence and psychopathology among methadone maintenance treatment clients should be considered when providing effectively targeted services to the drug using population.
\end{abstract}

Keywords: Opiate dependence; alcohol dependence; anxiety; depression; methadone.

\section{Introduction}

The Celtic Tiger phenomenon in Ireland was accompanied, among the general population, by an increase of $41 \%$ in alcohol consumption per capita between 1989 and $1999 .{ }^{1}$ Also in Ireland $27 \%$ of males and $21 \%$ of females consume in excess of the recommended weekly limits of alcohol of 21 units for males and 14 units for females ${ }^{2}$ even though alcoholism is known to result in social, psychosocial, legal, economic and medical problems. ${ }^{3}$

Consumption in excess of the recommended weekly limits is highest among males aged 18-34 and among semi-skilled and unskilled individuals. International research data indicates that alcohol misuse is also widely prevalent among drug users. ${ }^{4}$ Alcohol consumption may be higher among methadone users than non-users of the same age in the general population ${ }^{5}$ and approximately $50 \%$ of methadone maintenance treatment programme clients may be alco-

*Edward MacManus, MSc, Clare Fitzpatrick, Senior Clinical Psychologist, Psychology Department, Drugs and AIDS Service, Bridge House, Cherry Orchard Hospital, Ballyfermot,

Dublin 10, Ireland.

${ }^{*}$ Correspondence

SUBMITTED: JANUARY 6, 2005. ACCEPTED: OCTOBER 17, 2006. holics. ${ }^{6}$ It is also worth remembering that illicit drug users do not generally confine their drug use to one primary drug.?

Darke and Zador ${ }^{7}$ proposed that the majority of heroinrelated deaths are not due to heroin overdose but rather that to the synergistic effect of multiple drug use, including central nervous system depressants such as alcohol. While the use of a number of drugs including cocaine and amphetamines may have negative consequences when taken concurrently with heroin, studies have focused in particular on the misuse of central nervous system depressants such as alcohol among heroin users in drug treatment. ${ }^{8 \cdot 10}$

Polydrug use among heroin users is a serious problem both in relation to health outcomes and to the design of effective drug treatment programmes. ${ }^{4,8-10}$ Research on polydrug use among methadone maintenance treatment clients in Ireland indicates significant levels of multiple drug use. Urinanalysis results from five Eastern Regional Health Authority (ERHA) Addiction Centres show an aggregate clinic total of $65 \%$ positive for benzodiazepines, $30 \%$ positive for opiates and $14 \%$ positive for tricyclics ${ }^{11}$ and these findings may point to increasing polydrug misuse.

Psychopathology also frequently co-exists with drug dependence among opiate misusers entering treatment, ${ }^{12}$ there is some evidence of higher levels of comorbidity among those on methadone programmes ${ }^{13}$ and research findings indicate high rates of generalised anxiety disorder, depression, mood disorders and phobias among opiate users in treatment. ${ }^{14,15}$ Alcohol dependent drug users in particular may be at risk of developing psychiatric conditions. ${ }^{6}$ Alcohol use by heroin users in methadone maintenance treatment can lead to a reduction in positive response to treatment ${ }^{16}$ and there may be a substitution effect between improvements in illicit drug use and continued heavy drinking. ${ }^{4}$ Therefore programmes aimed at reducing polydrug use, particularly alcohol misuse, may need to be prioritised.

This study aimed to assess the prevalence of substance use, particularly alcohol use, and mood state (specifically the symptoms of anxiety and depression) among clients receiving methadone maintenance treatment for opiate misuse in Ireland and expected to find polydrug use, high levels of alcohol use and symptoms of anxiety and depression. Consequently brief, fully structured interviews took place with clients in attendance at two methadone maintenance treatment clinics in Dublin.

\section{Materials and methods}

Procedure

Ethical approval for the present study was received from 
the Ethics Committee, Trinity College, Dublin. The researcher was part employed by the Psychology Department, Drugs/AIDS Service, Cherry Orchard Hospital, Ballyfermot, Dublin. Initially, 131 names (25\% of the total number of clients receiving daytime methadone maintenance treatment) were randomly chosen by selecting every fourth name from the list of clients attending the two methadone maintenance treatment clinics. The researcher then approached all clients whose names were on the revised list when they presented for treatment. The study was outlined and clients were asked if they would voluntarily participate in a brief, confidential interview. Clients who were willing but unable to participate when approached were approached again at a later date, to a maximum of three times.

Fully structured interviews (lasting approximately 20 minutes) between the researcher and the 55 methadone maintenance treatment clients who agreed to participate took place in the clinics. Interviews took place under the supervision of the senior clinical psychologist with the Drugs/AIDS Service and the researcher received training in the implementation of the three instruments. Participants signed a consent form which provided information on the research and assured confidentiality and anonymity.

The three instruments were employed in the order in which they are described in the section on materials that follows. All interviews took place between February 2002 and February 2003. Participants' responses were subsequently encoded and analysed. Clients were able to obtain feedback on their interview from the senior clinical psychologist.

\section{Materials}

Three instruments were administered verbally during the brief, fully structured interviews: the Maudsley Addiction Profile (MAP), the Alcohol Dependence Scale (ADS) and the Hospital Anxiety and Depression Scale (HADS).

The Maudsley Addiction Profile is a 60 item scale and includes five subscales:

1. General management information

2. Substance use

3. Health risk behaviour

4. Health symptoms

5. Personal/social functioning.

The MAP refers to the 30 days prior to interview. The $M A P^{17}$ has good test-retest reliability (for example, retest reliability coefficients for subscales three, four and five average 0.81 ). The MAP also has good factorial validity (correlations between factors extracted from a range of scores do not exceed 0.12 in absolute value, $p>0.05$ ).

The Alcohol Dependence Scale is a 25 item scale and assesses levels of dependence on alcohol on five levels:

- No dependence

- Low

- Moderate

- Substantial

- Severe dependence.

The ADS refers to the 12 months prior to interview. The ADS ${ }^{18}$ has good internal consistency reliability (Cronbach alpha) at 0.92 and test-retest reliability at $0.92 .19 \mathrm{It}$ also has good predictive validity.

The Hospital Anxiety and Depression Scale ${ }^{20}$ is a 14 item scale which is scored out of 21 . It assesses levels of anxiety and depression on four levels: normal (0-7), mild (8-10), moderate (11-14), and severe (15-21). The HADS refers to the week prior. Factor analyses of HADS indicate a two factor solution in good accordance with the anxiety and depression subscales, with correlations between the two varying from 0.40-0.74 (mean of 0.56). ${ }^{21}$ Cronbach's alpha for the anxiety subscale are in the range of 0.68-0.93 (mean 0.83 ) and for the depression subscale of $0.67-0.90$ (mean 0.82). Correlations between HADS and other often used questionnaires range from $0.49-0.83 .{ }^{21}$

\section{Results}

\section{Statistical analysis}

Scores on the MAP, ADS and HADS were encoded and parametric and non-parametric statistical analyses were performed. Continuous variables were collapsed into categorical variables where required, errors were screened, normality was assessed, outliers were checked, and normal distribution and homogeneity of variance were assessed where necessary.

The relationship between the anxiety and depression subscales of the HADS was investigated using Pearson product-moment correlation coefficient. Preliminary analyses were performed to ensure no violation of the assumptions of normality, linearity, and homoscedasticity. There was a positive correlation between the two variables $[r=0.73, n=54$, $p=0.01]$, with high levels of anxiety associated with high levels of depression.

The relationship between number of substances used and the presence of symptoms of anxiety (as measured on the HAS) was investigated using Pearson product-moment correlation coefficient. Preliminary analyses were performed to ensure no violation of the assumptions of normality, linearity and homoscedasticity. There was a medium, positive correlation between the two variables $[r=0.34, n=54$, $\mathrm{p}<0.05]$.

A one-way between-groups multivariate analysis of variance was also performed to investigate sex differences on psychological well-being. Two dependent variables were used: HAS scores and HDS scores. The independent variable was gender. When the results for the dependent variables were considered separately, the only difference to reach statistical significance using a Bonferroni adjusted alpha level of 0.025 was anxiety: $F(1,52)=6.9, p=0.011$, partial eta squared $=0.07$. An inspection of the mean scores indicated that females had higher HAS scores (mean = $11.57, \mathrm{SD}=5.03)$ than males $($ mean $=8, S D=4.94)$.

\section{Participants}

Participants were 55 out of 131 methadone maintenance treatment clients approached by the researcher, giving a response rate of $42 \%$, in attendance at two South Western Area Health Authority drug treatment clinics in Dublin. The clinics were situated in Castle Street in Dublin city centre and in the Aisling Clinic, Cherry Orchard Hospital, Ballyfermot. The mean age of the sample was 29.3 years (SD 6.5, range $21-49$ ) and $52.7 \%$ of participants were female. This created a higher than usual female to male ratio as approximately $70 \%$ of clients in attendance for methadone maintenance treatment in Dublin are male. The majority of participants were unemployed (72.7\%) and came from the clinics' catch- 
ment areas, which are characterised by social and economic disadvantage.

Table 1 shows the results from the sample's scores on the ADS, HAS and HDS. It shows the prevalence among the sample (expressed in percentages) of alcohol dependence (56\%: $95 \% \mathrm{Cl} 43 \%-69 \%$ ), symptoms of clinical anxiety (56\%: $95 \% \mathrm{Cl} 43 \%-69 \%$ ), and symptoms of clinical depression (42\%: 95\% Cl 30\%-55\%). Prevalence rates are expressed as level of severity: mild, moderate, and severe.

Table 2 shows the results from the sample's scores on the MAP 2) substance use subscale. It shows the percentage of the sample which used each of the drugs (percentages are rounded upwards). Table 2 also shows the mean daily amount consumed by users of each substance, as expressed in the relative measure for each substance. Women consumed on average approximately eight units (mean $=8.4$, $\mathrm{SD}=4.7$ ) of alcohol each day while men consumed on average approximately 13 units (mean $=12.7, S D=6.7$ ) of alcohol each day.

\section{Discussion}

The major finding of the present study was that of the $56 \%$ of respondents who drank all showed some level of alcohol dependence. Scores on the ADS indicate that all clients who used alcohol (56.4\%) were also to some extent dependent. The mean daily amount of alcohol consumed (approximately eight units for women and 13 units for men) also placed alcohol users in this sample well above the safer limits of weekly alcohol consumption. The levels of alcohol dependence in this study are similar to those found in other studies, such as Gossop et al. ${ }^{4}$

The use of alcohol is socially condoned in Ireland and there has been a large increase in the per capita consumption of alcohol in Ireland in recent years. ${ }^{1}$ Nevertheless the findings from the present study indicate particularly high levels of alcohol dependence among this methadone maintenance treatment sample and may suggest a possible 'substitution effect.'. ${ }^{4}$ Clients may be replacing one substance, heroin, for another, alcohol. A significant minority (44\%) in this study consumed no alcohol. This high abstinence rate is also greater than that expected in the general population, as found in Gossop et al. ${ }^{4}$ While such an undertaking was outside the scope of this study, an investigation of patterns of alcohol use among methadone maintenance treatment clients may be warranted so as to elucidate the reasons for such atypical patterns of alcohol consumption.

The second finding of this study was that over half (56.4\%) of methadone maintenance treatment clients presented with the symptoms of clinical anxiety and a large minority (41.8\%) presented with the symptoms of clinical depression. While it is worthwhile remembering that clinical populations tend to present higher levels of psychopathology than general populations, ${ }^{22}$ these prevalence rates are much higher than those expected among the general population. In Ireland approximately $5 \%$ of the general population have clinical depression and this figure may rise to approximately $10 \%$ among those in attendance in the GP surgery. ${ }^{23}$ While correlations of 0.6 between the anxiety and depression subscales of the HADS are commonly reported in the literature, ${ }^{21}$ suggesting that this instrument may not be measuring anxiety and depression separately, the present study found that greater symptoms of
Table 1: Prevalence of alcohol dependence, symptoms of clinical

anxiety, and symptoms of clinical depression among 55 clients on methadone maintenance treatment

$\begin{array}{lccc}\text { Severity } & \begin{array}{c}\text { Alcohol } \\ \text { dependence (\%) }\end{array} & \text { Anxiety (\%) } & \text { Depression (\%) } \\ \text { Mild } & 44 & 16 & 11 \\ \text { Moderate } & 11 & 18 & 22 \\ \text { Severe } & 2 & 22 & 9 \\ \text { Total } & \mathbf{5 6} & \mathbf{5 6} & \mathbf{4 2}\end{array}$

\section{Table 2: Prevalence and mean daily quantity of drug use}

$\begin{array}{lcc}\text { Drug } & \text { Sample (\%) } & \text { Mean daily drug use } \\ \text { Cannabis } & 66(n=36) & 3 \text { joints } \\ \text { Alcohol } & 56(n=31) & 6 \text { units } \\ \text { Heroin } & 40(n=22) & 0.4 \mathrm{~g} \\ \text { Illicit benzodiazepines } & 29(\mathrm{n}=16) & 5 \text { pills } \\ \text { Illicit methadone } & 26(\mathrm{n}=14) & 0.06 \mathrm{~g} \\ \text { Amphetamines } & 0 & 0 \\ \text { Crack cocaine } & 0 & 0 \\ \text { Other } & 11(\mathrm{n}=6) & -\mathrm{a} \\ \text { 'measures vary } & & \end{array}$

anxiety were associated with greater symptoms of depression. The demotivating and debilitating effects of psychiatric conditions on methadone maintenance treatment participation in studies such as El Bassel et a ${ }^{\beta}$ is noteworthy. The combined effect of substance use and psychiatric difficulties may negatively impact on clients' ability to make rational, informed choices regarding methadone maintenance treatment participation and substance use.

The third finding of this study was that the number of substances used by the sample ranged from one to six and the majority (77\%) used between one and three substances. The majority of these were central nervous system depressant users which suggests a serious risk of complications due to multiple drug toxicity. There was also a large minority $(18 \%)$ using between four to six substances. This high level of polydrug use, as suggested by other studies on methadone maintenance treatment programmes in Ireland, ${ }^{11}$ poses a serious threat to the physiological and psychological health of methadone maintenance treatment clients.

Findings from this study indicate that the greater the number of substances used by methadone maintenance treatment clients the greater the prevalence of psychopathological symptomatology, specifically the symptoms of anxiety disorder. Indeed the high prevalence rates of symptoms of both anxiety and depressive disorders in the present study may indicate a substantial psychologically dysfunctional subgroup.

A fourth finding of this study was the significant gender differences in relation to the symptoms of psychopathology, with females reporting significantly higher levels of symptoms of anxiety. Nevertheless these differences in reported symp- 
toms of psychopathology could be assessed with caution as they may indicate underreporting of psychological distress by males. Also in relation to gender there was a larger than usual response by females in this study $(52.7 \%)$ whereas the majority (approximately 70\%) of clients receiving methadone maintenance treatment in Dublin are male.

This larger number of females may have influenced the estimated prevalence of the symptoms of anxiety, as females can yield higher scores on these scales. Also of note in relation to sampling is that, while the response rate in the study was $42 \%$, the similarities and/or differences between those clients who refused to participate and those who took part were not assessed leading to the possibility of sampling bias.

This study found significant levels of alcohol dependence and anxiety and depressive disorder symptomatology among this methadone maintenance treatment sample. At the treatment clinics in question clients receive multidisciplinary input from nurses, social workers, pharmacists, psychiatrists and clinical psychologists tasked with identifying and treating addictions and psychiatric disorders.

However the present study suggests that international trends in polydrug use, alcohol use and in the prevalence of mood disorders among methadone maintenance treatment clients may also exist in the Irish context. Interventions aimed at reducing alcohol use and psychopathology among methadone maintenance treatment clients must be warranted as well as increased screening for these disorders.

In particular, further investigation of the relationship between psychiatric symptoms and alcohol abuse is warranted. Services could be created to meet the needs of methadone maintenance treatment clients who present with alcohol dependence and coexisting anxiety and depressive disorders.

To effectively address these difficulties protocols could be introduced whereby all drug users presenting for methadone maintenance treatment are automatically screened for alcohol use and dependence and psychopathology.
Declaration of Interest: None

References

1. Department of Health and Children. Strategic Task Force on Alcohol: Interim Report. Dublin: Department of Health and Children; 2002.

2. Friel S, Nic Gahhainn S, Kelleher C. The National Health and Lifestyle Surveys (SLAN, HBSC). Galway: Centre for Health Promotion Studies, National University Ireland; 1999.

3. Bradley KA, Kivlahan DR, Bush KR, McDonnell MB, Fihn SD. Variations of the CAGE alcohol screening questionnaire: strengths and limitations in VA general medical alcohol screening questionnaire: strengths and limitations

4. Gossop M, Marsden J, Stewart D, Rolfe A. Patterns of drinking and drinking 4. Gossop M, Marsden J, Stewart D, Rolfe A. Patterns of drinking and drinking
outcomes among drug misusers 1-year follow-up results. J Subst Abuse Treat 2000; 19: 45-50.

5. Hunt DE, Strug DL, Goldsmith DS. Alcohol use and abuse: heavy drinking among methadone clients. Am J Drug Alcohol Abuse 1986; 12(1/2): 147-164.

6. El-Bassel N, Schilling RF, Turnbull JE, Su KH. Correlates of alcohol use among methadone patients. Alcohol Clin Exp Res 1993; 17(3): 681-686.

7. Darke S, Zador D. Fatal heroin 'overdose': a review. Addiction 1996; 91 (12): 17651772 .

8. Ross J, Darke S, Hall W. Benzodiazepine use among heroin users in Sydney: patterns of use, availability and procurement. Drug Alcohol Rev 1996; 15: 237-243.

9. Rooney S, Kelly G, Bamford L, Sloan D, O'Connor J. Co-abuse of opiates and 9. Rooney S, Kelly G, Bamford L, Sloan D, O'Con

benzodiazepines. Ir J Med Sci 1990; 168 (1): 36-41. 10. Chatham LR, Rowan-Szal GA, Joe GW, Simpson DD. Heavy drinking, alcoholdependent vs. nondependent methadone-maintenance clients: a follow-up study. Addict Behav 1997; 22: 69-80

11. Farrell M, Gerada C, Marsden J. External review of drug services for the Eastern Health Board. London: National Addiction Centre, Institute of Psychiatry; 2000. 12. Rounsaville B, Kleber H. Untreated opiate addicts: How do they differ from those seeking treatment? Arch Gen Psychiatry 1985; 42(11): 1072-1077.

13. Galbaud du Fort G, Newman SC, Bland RC. Psychiatric comorbidity and treatment seeking. Sources of selection bias in the study of clinical populations. Nerv Ment Dis 1993; 181(8): 467-474.

14. Rounsaville B, Weissman M, Kleber H, Wilber C. Heterogeneity of psychiatric diagnosis in treated opiate addicts. Arch Gen Psychiatry 1982; 39(2): 161-166. In: Hogan DM. Annotation: the psychological development and welfare of children of opiate and cocaine users: review and research needs. J Child Psychol Psychiatry 1998; 39(5): $609-620$

15. Williams H, O'Connor J, Kinsella A. Depressive symptoms in opiate addicts on 15. Williams H, O'Connor J, Kinsella A. Depressive symptoms
methadone maintenance. Ir J Psychol Med 1990; 7(1): 45-46.

16. Lowinson JH, Marion IJ, Joseph H, Dole VP. Methadone Maintenance. In: Lowinson 16. Lowinson JH, Marion IJ, Joseph H, Dole VP. Methadone Maintenance. In: Lowinson
JH, Ruiz P, Millman R, Langrod J. Substance Abuse: A Comprehensive Textbook.

Baltimore: Williams \& Williams, 1992: 550-561. assessing treatment outcome. Addiction 1998; 93(12): 1857-1868.

18. Horn J, Skinner H, Wanberg K, Foster F. Alcohol Use Questionnaire/Alcohol Dependence Scale (ADS). Ontario: Centre for Addiction and Mental Health; 1984. 19. Skinner H, Horn J. Alcohol Dependence Scale (ADS) User's Guide. Ontario: Centre for Addiction and Mental Health; 1984.

20. Zigmond A, Snaith R. The Hospital Anxiety and Depression Scale. Acta Psychiatr Scand 1983; 67: 361

21. Bjelland I, Dahl AA, Haug TT, Neckelmann D. The validity of the Hospital Anxiety and Depression Scale. An updated literature review. J Psychom Res 2002; 52 (2): 6977.

22. Weiss R, Mirin S, Griffin M. Methodological considerations in the diagnosis of coexisting psychiatric disorders in substance misusers. Br J Addict 1992; 87 (2): 179187.

23. McKeon P. Suicide in Ireland. A global perspective and a national strategy. Dublin: Aware Publications; 1998. 